\title{
Aggressive Cancer Behavior of Latent Gleason Pattern 5 in Prostatectomy Specimens
}

\author{
TETSUYA FUJIMURA ${ }^{1}$, HIROSHI FUKUHARA ${ }^{2}$, YUTA YAMADA ${ }^{3}$, SATORU TAGUCHI ${ }^{2}$, \\ TORU SUGIHARA ${ }^{1}$, AYA NIIMI $^{3}$, MASAKI NAKAMURA ${ }^{3}$, TOHRU NAKAGAWA ${ }^{4}$, \\ YASUHIKO IGAWA ${ }^{5}$, YUKIO HOMMA ${ }^{5}$ and HARUKI KUME ${ }^{3}$ \\ ${ }^{1}$ Department of Urology, Jichi Medical University, Tochigi, Japan; \\ ${ }^{2}$ Department of Urology, Kyorin University, Tokyo, Japan; \\ ${ }^{3}$ Department of Urology, Graduate School of Medicine, The University of Tokyo, Tokyo, Japan; \\ ${ }^{4}$ Department of Urology, Teikyo University School of Medicine, Tokyo, Japan; \\ ${ }^{5}$ Department of Urology, Japan Red Cross Hospital, Tokyo, Japan
}

\begin{abstract}
Background/Aim: The aim of this study was to demonstrate the clinical significance of latent Gleason pattern (GP) 5 occasionally found in prostatectomy specimens. Materials and Methods: Patients ( $n=605)$ undergoing radical prostatectomy were classified into three groups according to the presence of GP5 in the biopsy or in the prostatectomy specimens: 'GP5 negative', absence of GP in both specimens 'latent GP5', absence of GP5 in the biopsy specimen, but presense of GP5 in the prostatectomy specimen, and 'GP5 positive', presense of GP in both specimens. The characteristics of these three groups were analyzed. Results: There were 381 men in the GP5-negative group, 155 in the latent GP5 group, and 69 in the GP5positive group. Low- or intermediate-risk for prostate cancer, latent GP5 and surgical margin positivity were independent predictors of biochemical recurrence (Hazard ratio (HR): 3.1, 5.8 , respectively, $p=0.001,0.0002$, respectively). Conclusion: Latent GP5 is an important prognostic factor that should be evaluated in patients with low-and intermediate-risk for prostate cancer before the initiation of treatment.
\end{abstract}

Therapeutic strategies for prostate cancer (PC) should comply with guidelines published by the National Comprehensive Cancer Network or European Urological Association $(1,2)$. These guidelines utilize age, serum prostate-specific antigen (PSA) levels, Gleason score (GS) in the biopsy specimen, and clinical stages to navigate

Correspondence to: Tetsuya Fujimura, Department of Urology, Jichi Medical University, 3311-1, Yakushiji, Simotsuke-shi, Tochigi 3290498, Japan. Tel: +81 285587379, e-mail: tfujimura@jichi.ac.jp

Key Words: Biochemical recurrence, Gleason score, prostate cancer, prognosis, robot-assisted radical prostatectomy. therapeutic strategies. These clinical parameters, however, do not sufficiently predict biological aggressiveness of PC or duration of treatments. The identification of mutations in genes such as $A T M$ and $B R C A l / 2$ or the expression of specific genes may provide further information on the metastatic potential or radio-sensitivity $(3,4)$.

Pathology reports on surgical specimen can also be used to predict outcome and suggest clinical management. The reports occasionally reveal upgrading of Gleason pattern (GP) in surgical specimens compared with results from biopsy samples. A study on 7,643 men undergoing RP found that $36.3 \%$ of men with GS 6 or less at prostate needle biopsy showed upgrading of GP in prostatectomy specimens (5). In particular, GP5 is an ominous or lethal phenotype of PC requiring intensive treatments (6-8). Latent GP5, GP5 not detected at biopsy, but firstly found in the surgical specimen, may have significant impact on clinical management. However, the incidence of latent GP5 or its clinical significance has not been fully investigated. Here, the characteristics of latent GP5 were recorded and its predictors in men with D'Amico low- or intermediate-risk for PC that had undergone robot-assisted radical prostatectomy (RARP) were identified.

\section{Patients and Methods}

Patients. We reviewed medical records of 605 men who underwent RARP for localized PC at the University of Tokyo Hospital between November 1, 2011 and August 31, 2017. The records were evaluated by two pathologists and 'latent GP5' was defined as a pathology showing absence of GP5 in the biopsy specimen, and presence of GP5 in the surgical specimen. Patients were classified into three groups according to the presence of GP5: 'GP5 negative' group, absence of GP in both specimens, 'latent GP5' group; absence of GP5 in the biopsy specimen, but presense of GP5 in the prostatectomy specimen including primary, secondary, and tertiary 
Table I. Patient's characteristics $(n=605)$.

\begin{tabular}{|c|c|c|c|}
\hline & GP 5 negative $(\mathrm{n}=381)$ & Latent GP $5(n=155)$ & GP $5(n=69)$ \\
\hline Age, median (range) & $66(47-78)$ & $67(49-77)$ & $67(52-80)$ \\
\hline \multicolumn{4}{|l|}{ Complication $(\%)$} \\
\hline Hypertension & $122(32)$ & $46(30)$ & $20(29)$ \\
\hline Diabetes mellitus & $56(15)$ & $24(16)$ & $15(22)$ \\
\hline Hyperlipidemia & $44(13)$ & $13(9)$ & $7(10)$ \\
\hline Angina pectoris & $33(9)$ & $13(9)$ & $1(1.5)$ \\
\hline Serum PSA (ng/ml), median (range) & $7.0(1.4-63)$ & $9.3(2.5-56)$ & $9.4(4.1-71)$ \\
\hline Estimated prostate volume $\left(\mathrm{cm}^{3}\right)$, median (range) & $28(12-130)$ & $28(12-88)$ & $27(12-127)$ \\
\hline Positive core rate of the prostate biopsy (\%), median (range) & $22(5-100)$ & $25(6-100)$ & $50(6-100)$ \\
\hline \multicolumn{4}{|l|}{ Biopsy Gleason score $(\%)$} \\
\hline $3+3$ & $96(25)$ & $10(6)$ & $0(0)$ \\
\hline $3+4$ & $182(48)$ & $57(37)$ & $0(0)$ \\
\hline $4+3$ & $60(16)$ & $41(26)$ & $0(0)$ \\
\hline $3+5$ & $0(0)$ & $0(0)$ & $5(7)$ \\
\hline $4+4$ & $43(11)$ & $47(30)$ & $0(0)$ \\
\hline $5+3$ & $0(0)$ & $0(0)$ & $2(3)$ \\
\hline $4+5$ & $0(0)$ & $0(0)$ & $47(68)$ \\
\hline $5+4$ & $0(0)$ & $0(0)$ & $12(17)$ \\
\hline $5+5$ & $0(0)$ & $0(0)$ & $3(4)$ \\
\hline \multicolumn{4}{|l|}{ D'Amico classification (\%) } \\
\hline Low & $74(19)$ & $8(5)$ & 0 \\
\hline Intermediate & $250(66)$ & $92(60)$ & 0 \\
\hline High & $57(15)$ & $55(35)$ & $69(100)$ \\
\hline
\end{tabular}

GP: Gleason pattern.

pattern, and GP5 group, presense of GP in both specimens. Clinicopathological parameters including age, serum PSA levels $(\mathrm{ng} / \mathrm{ml})$ at biopsy, serum C-reactive protein (CRP) levels ( $\mathrm{ng} / \mathrm{ml})$ before surgery, estimated prostate volume $\left(\mathrm{cm}^{3}\right)$, positive core rate of the prostate biopsy (\%), pathological results, D'Amico risk classification (9), and clinical outcomes were compared among the three groups. Prostate volume was calculated by preoperative computed tomography, or magnetic resonance imaging. Our standard protocol for initial biopsy was transrectal ultrasonography-guided twelve-core biopsies. Transperineal ultrasonography-guided sextant biopsies were added in the repeated biopsy. Pathology of biopsy and surgical specimens were evaluated by two pathologists. Patients who had received neo-adjuvant androgen deprivation therapy (ADT) or $5 \alpha$ reductase inhibitor were excluded.

The study was approved by the ethics committee of the hospital and written informed consent was obtained from each patient before surgery. Patients were followed by their surgeons at three-month intervals for 5 years and annually thereafter. Biochemical recurrence (BCR) was defined as a consecutive increase in serum PSA levels over $0.2 \mathrm{ng} / \mathrm{ml}$.

Surgical techniques. We carried out RARP using the peritoneal approach, as previously described (10). Cavernous nerve preservation was recommended on the cancer-negative side, and were conducted on patient's request. Bilateral preservation was done if the cancer was located at the transitional zone. By using the Japan PC nomogram, extended lymph node dissection was performed in men who had a $5 \%$ or more probability of lymph node metastasis (11).
Statistical analysis. Age, serum PSA levels, serum CRP levels, prostate volume, and the positive core rate of the biopsy were compared between GP5 negative group and latent GP5 group using the Wilcoxon test. Association with clinicopathological findings was assessed using the chi-square test. BCR-free survival curves were plotted using the Kaplan-Meier method, and were compared using the Log-rank test. Predictors of latent GP5 were identified by multivariate analysis using variables selected by the stepwise method with $>2 \mathrm{~F}$ values (12). JMP 13.0 software (SAS Institute, Cary, NC, USA) was used for the analysis. $p<0.05$ was considered to be statistically significant.

\section{Results}

In the whole cohort, median values of age, serum PSA level at diagnosis, serum CRP level, prostate volume, and positive core rate of the prostate biopsy were 67 years, $7.6 \mathrm{ng} / \mathrm{ml}$, $0.05 \mathrm{ng} / \mathrm{ml}, 27 \mathrm{~cm}^{3}$, and $25 \%$, respectively. Latent GP5 group had intermediate values of PSA levels, positive core rate, and D'Amico classification between the GP5 negative group and the GP5 group (Table I). Eight out of 82 men $(9.8 \%)$ at low-risk and 92 out of 342 men (27\%) at intermediate-risk were designated as the latent GP5 Group.

Men with primary and secondary GS of $3+4(n=30), 4+3$ $(n=59), 4+4(n=8)$ had tertiary GP5, and thus were classified as latent GP5 Group. Latent GP5 group showed intermediate features regarding pathological findings in surgical specimens (Table II). 
Table II. Pathological findings of prostatectomy specimens ( $n=605)$.

\begin{tabular}{|c|c|c|c|}
\hline Factors $(\%)$ & GP 5 negative $(n=381)$ & Latent GP $5(\mathrm{n}=155)$ & GP $5(n=69)$ \\
\hline \multicolumn{4}{|l|}{ T stage } \\
\hline 0 & $1(0.2)$ & $0(0)$ & 0 \\
\hline $2 \mathrm{a}$ & $49(13)$ & $9(6)$ & $2(3)$ \\
\hline $2 b$ & $52(14)$ & $9(6)$ & $2(3)$ \\
\hline $2 \mathrm{c}$ & $197(52)$ & $66(42)$ & $17(25)$ \\
\hline $3 a$ & 73 (19) & $51(33)$ & $27(39)$ \\
\hline $3 b$ & $9(2)$ & $20(13)$ & $21(30)$ \\
\hline $\mathrm{N}$ stage $(\mathrm{n}=206)$ & 1 & $1(0.9)$ & $1(1.4)$ \\
\hline \multicolumn{4}{|l|}{$9(17)$} \\
\hline \multicolumn{4}{|l|}{ Gleason score } \\
\hline $3+3$ & $27(7)$ & $0(0)$ & $0(0)$ \\
\hline $3+4$ & $202(53)$ & $30 *(19)$ & $5^{*}(7)$ \\
\hline $4+3$ & $103(27)$ & $59 *(38)$ & $6^{*}(8)$ \\
\hline $3+5$ & 0 & $6(4)$ & $2(3)$ \\
\hline $4+4$ & $49(13)$ & $8^{*}(5)$ & $3 *(4)$ \\
\hline $5+3$ & 0 & $1(0.7)$ & 0 \\
\hline $4+5$ & 0 & $47(30)$ & $41(60)$ \\
\hline $5+4$ & 0 & $4(3)$ & $11(16)$ \\
\hline $5+5$ & 0 & $0(0)$ & $1(1)$ \\
\hline Positive perineural invasion & $257(68)$ & $132(85)$ & $59(86)$ \\
\hline Positive lymphovascular invasion & $34(9)$ & $38(24)$ & $35(50)$ \\
\hline Positive vascular invasion & $119(31)$ & $84(54)$ & $51(74)$ \\
\hline Positive resection margin & $57(15)$ & $54(35)$ & $28(23)$ \\
\hline
\end{tabular}

GP: Gleason pattern; *Tertiary GP5.

At the end of follow-up (median 22 months, range $=1-72$ months) 14 patients $(3.7 \%)$ in the GP5 negative, 24 (15\%) in the latent GP5, $19(28 \%)$ in the GP5 group experienced $\mathrm{BCR}$. The BCR-free survival rate was significantly worse in the latent GP5 and the GP5 group compared with that of the GP5 negative group $(p<0.0001$, Figure 1$)$. Interestingly, the BCR-free rate was higher in the latent GP5 than the GP5 group until 48 months post-surgery, when the BCR-free rate was reversed (59\% and $66 \%$, respectively).

Subgroup analysis among 100 men with low- or intermediate risk demonstrated that the latent GP5 group had significantly higher age, higher PSA levels, higher PSA density, and significantly higher positive core rate compared with the GP negative group ( $p=0.02,0.01,0.003$, and 0.003 , respectively) (Table III). Of the 100 men in the latent GP5 group, $69(70 \%)$ had tertiary GP5. In these men with lowand intermediate-risks, the BCR-free rate was significantly worse in the latent GP5 group than in the GP5 negative group ( $p<0.0001$, Figure 2$)$.

Multivariate analysis of BCR risk revealed that latent GP5 and positive surgical margin were independent predictive factors (Hazard ratio: 3.1, 5.8, respectively, $p=0.001,0.0002$, respectively) (Table IV).

In order to predict the probability of latent GP5, preoperative variables including age, complication, serum
PSA, estimated prostate volume, PSA density, serum CRP levels, D'Amico risk, presence of GP4 were analysed by the stepwise method with $>2 \mathrm{~F}$ values (Table III) (12). High age (>69 years), high serum CRP level (>0.09 ng/ml), dominant GP4 in biopsy samples, D'imico intermediate risk, diabetes mellitus, and lack of hyperlipidemia predicted latent GP5 with a 0.71 area under the curve.

\section{Discussion}

Histopathological examination of prostatectomy specimens occasionally detects GP5 in men who have negative findings of GP5 in the biopsy samples. 'Latent GP5', as we call it, was found in $155(26 \%)$ of 605 men which had undergone RARP, and in $9.8 \%$ of men with D'Amico low-risk and $27 \%$ of men with intermediate-risk. Latent GP5 was associated with advanced pathological stage and poor outcomes compared with men free of GP5. In a subgroup of low- and intermediate-risk men, latent GP5 was an independent prognostic factor of recurrence.

The prevalence of latent GP5 was relatively high compared to a previous study, which demonstrated that 59/5071 (1.1\%) patients with biopsy GS6, 48/1577 (3\%) with biopsy GS3+4, and 83/615 (13\%) with biopsy GS4+3 experienced upgrading to GS8-10 (5). Recently, aggressive 


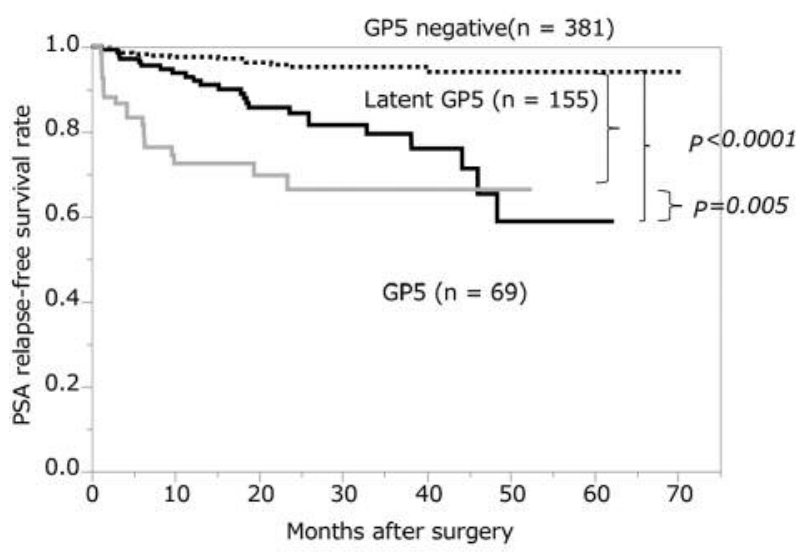

Figure 1. Prostate-specific antigen (PSA) relapse-free curves in patients who underwent robot-assisted radical prostatectomy $(n=605)$. PSA relapse-free survival rates in patients with Gleason pattern (GP) 5 negative (dotted line, $n=381$ ), those with latent GP5 (black line, $n=155$ ), and those with GP5 (gray line, $n=69$ ). The PSA relapse-free survival rate was significantly worse in patients with GP5 than those without GP5 $(p<0.0001)$, and was almost similar in latent GP5 and GP5 groups at the end of the follow-up period.

behavior of tertiary GP5 was reported in radical prostatectomy specimens, however, there were no data from biopsy samples $(13,14)$. To best of our knowledge, this is the first report demonstrating clinical significance of latent GP5 based on analysis of both biopsy and prostatectomy samples.

Five-year BCR-free survival was $89.6 \%, 80.6 \%, 72.8 \%$, and $58.2 \%$ for $3+4=7,3+4+$ tertiary GP5, $4+3=7$, and $4+3+$ tertiary GP5, respectively $(p<0.001)$, and GP5 was also independently associated with BCR (5). Recent reports showed that BCR in patients with latent GP5 was $57 \%$ at 5 years, which was almost equal to BCR of the high-risk group and $4+3+$ tertiary GP5 $(5,15)$. Even if patients were diagnosed as having low-risk for PC, the Rotterdam randomized study of screening for PC showed that 15 patients out of 98 (15\%) died of cancer (16). Primary GP4, $>50 \%$ positive biopsy cores, or having more than one D'Amico intermediate-risk factor (i.e., stage cT2b, PSA levels of $10-20 \mathrm{ng} / \mathrm{ml}$, or GS7) was known to be poor prognostic factors in the intermediate-risk group (17). These findings suggest that tumor characteristics in patients with low- and intermediate-risk are heterogeneous.

How can lethal PC including GP5 and non-lethal PC be predicted? Whole-exome analysis of germline DNA derived from the blood of 313 patients who had died from PC and 486 low-risk patients with localized PC, including EuropeanAmerican, African-American, and Chinese patients showed that the frequency of mutations in ATM and BRCAl/2 was $6.07 \%$ in lethal PC patients, which was significantly higher

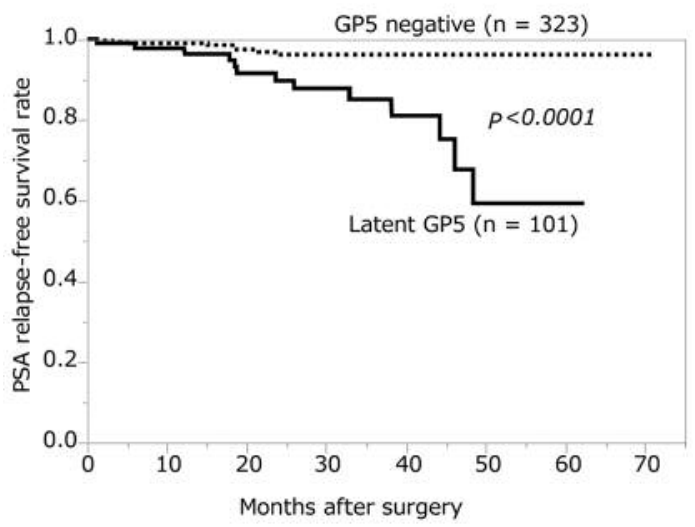

Figure 2. Prostate-specific antigen (PSA) relapse-free curves in low- and intermediate-risk patients. PSA-relapse in patients with latent GP5 was significantly lower compared with those to GP5-negative $(p<0.0001)$.

than that observed in patients with localized PC (1.44\%) (3). Another study showed that in 385 patients surgically treated for localized PC, 23 gene transcripts predicted metastaticlethal PC (17). A 24-gene molecular signature (postoperative radiation therapy outcomes score; PORTOS), which includes genes related to DNA damage by radiation and to the immune response, could be used to predict the incidence of distant metastasis after postoperative radiation (18). In the future, if molecular diagnosis is commercially available, more appropriate information can be provided to individuals in the low- and intermediate-risk groups.

How patients with GP5 or those with a high probability of having GP5 can be treated? We have previously investigated the clinical significance of salvage RT and salvage ADT for locally advanced PC (19-21). Men in the high-risk group that received RP following radiotherapy had significantly better cancer-specific and overall survival outcomes than patients who had firstly received radiotherapy (19). Early salvage radiotherapy is recommended before serum PSA rises to 0.5 $\mathrm{ng} / \mathrm{ml}(20,22)$. Salvage ADT is also beneficial at serum PSA levels of $0.1-0.2 \mathrm{ng} / \mathrm{ml}$ (21). Before the initial treatment decision of localized PC including active surveillance, brachytherapy, external radiotherapy, or RP (23), assessment for latent GP5 probability is necessary. Patients with GP5 or a high probability of having GP5 require surgical removal and earlier treatment to prevent the micro-seeding of metastasis by salvage radiotherapy or salvage ADT.

The present study has several limitations. First, the design was retrospective and observational at a single institution. Second, the follow-up period was relatively short. Third, prebiopsy MRI imaging was not routinely evaluated. Further investigation and follow-up data are needed to delineate the significance of latent GP5 in men with localized prostate cancer. 
Table III. Patient characteristics of low- and intermediate-risk groups $(n=423)$.

\begin{tabular}{|c|c|c|c|}
\hline & GP 5 negative $(n=323)$ & Latent GP $5(\mathrm{n}=100)$ & $p$-Value \\
\hline Age, median (range) & $67(47-78)$ & $69(51-76)$ & 0.02 \\
\hline \multicolumn{4}{|l|}{ Complication (\%) } \\
\hline Hypertension & $106(33)$ & $36(36)$ & 0.61 \\
\hline Diabetes mellitus & $45(14)$ & $19(19)$ & 0.24 \\
\hline Hyperlipidemia & $39(13)$ & $7(7)$ & 0.12 \\
\hline Angina pectoris & $26(9)$ & $11(12)$ & 0.41 \\
\hline Serum PSA (ng/ml), median (range) & $6.9(2.7-20)$ & $8.1(3.6-18)$ & 0.01 \\
\hline Estimated prostate volume, median (range) & $28(12-130)$ & $28(13-73)$ & 0.48 \\
\hline PSA density, median (range) & $0.23(0.05-3.5)$ & $0.3(0.09-0.9)$ & 0.003 \\
\hline Serum CRP (ng/ml), median (range) & $0.04(0-0.85)$ & $0.05(0.02-4.05)$ & 0.2 \\
\hline Positive core rate $(\%)$, median (range) & $22(5-100)$ & $25(6-83)$ & 0.003 \\
\hline \multicolumn{4}{|l|}{ D'Amico classification $(\%)$} \\
\hline Low & $74(23)$ & $8(8)$ & \multirow[t]{2}{*}{0.0003} \\
\hline Intermediate & $249(77)$ & $92(92)$ & \\
\hline \multicolumn{4}{|l|}{ Pathological Gleason score (\%) } \\
\hline $3+3$ & $26(8)$ & $0(0)$ & \multirow[t]{7}{*}{$<0.0001$} \\
\hline $3+4$ & $192(60)$ & $26^{*}(25)$ & \\
\hline $3+5$ & $0(0)$ & $4(4)$ & \\
\hline $4+3$ & $80(25)$ & $40 *(40)$ & \\
\hline $4+4$ & $25(7)$ & $3 *(3)$ & \\
\hline $4+5$ & $0(0)$ & $26(25)$ & \\
\hline $5+4$ & $0(0)$ & $1(1)$ & \\
\hline \multicolumn{4}{|l|}{ Pathological T stage (\%) } \\
\hline 0 & $1(0.3)$ & $0(0)$ & \multirow[t]{6}{*}{0.0003} \\
\hline $2 \mathrm{a}$ & $41(12)$ & $6(6)$ & \\
\hline $2 b$ & $44(14)$ & $6(6)$ & \\
\hline $2 \mathrm{c}$ & $173(54)$ & $48(48)$ & \\
\hline $3 a$ & $58(18)$ & $31(31)$ & \\
\hline $3 b$ & $6(2)$ & $9(9)$ & \\
\hline Positive perineural invasion (\%) & $217(67)$ & $84(84)$ & 0.0013 \\
\hline Positive lymphovascular invasion (\%) & $26(8)$ & $23(23)$ & 0.0002 \\
\hline Positive vascular invasion (\%) & $92(28)$ & $54(54)$ & $<0.0001$ \\
\hline Positive resection margin (\%) & $48(15)$ & $33(33)$ & $<0.0001$ \\
\hline
\end{tabular}

GP: Gleason pattern; *Tertiary GP5.

Table IV. Risk analysis of biochemical recurrence in low- and intermediate-risk groups $(n=423)$.

\begin{tabular}{|c|c|c|c|c|c|c|}
\hline \multirow[b]{2}{*}{ Variable } & \multicolumn{3}{|c|}{ Univariate } & \multicolumn{3}{|c|}{ Multivariate } \\
\hline & Hazard ratio & $95 \%$ index & $p$-Value & Hazard ratio & $95 \%$ index & $p$-Value \\
\hline Age & 1.0 & $0.94-1.1$ & 0.93 & - & - & - \\
\hline Serum PSA (ng/ml) & 1.0 & $0.91-1.1$ & 0.59 & - & - & - \\
\hline Latent GP5 (Yes vs. No) & 5.5 & $2.3-14$ & 0.0001 & 3.1 & $1.3-8.2$ & 0.001 \\
\hline Extra prostatic extension (Positive $v s$. Negative) & 1.6 & $0.62-3.9$ & 0.31 & - & - & - \\
\hline Lymphovascular invasion(Positive $v s$. Negative) & 2.6 & $0.85-6.6$ & 0.09 & 2.1 & $0.7-5.9$ & 0.19 \\
\hline Vascular invasion (Positive $v s$. Negative) & 3.5 & $1.5-8.8$ & 0.005 & 2.0 & $0.8-5.3$ & 0.14 \\
\hline Perineural invasion (Positive vs. Negative) & 2.4 & $0.87-8.2$ & 0.09 & - & - & - \\
\hline Resection margin (Positive vs. Negative) & 7.0 & $2.9-17$ & $<0.0001$ & 5.8 & $1.3-15$ & 0.0002 \\
\hline
\end{tabular}




\section{Conclusion}

Latent GP5 was an important predictor of surgical outcomes and its probability should be estimated in men with low- and intermediate- risks before initial local treatment.

\section{Conflicts of Interest}

All Authors declare no conflict of interest.

\section{Acknowledgements}

The Authors would like to thank emeritus president Katsuki Kawabe; Tokyo Teishin Hospital, Dr.Yasunori Ishii; Ishii Medical Clinic, and emeritus Prof. Tadaichi Kitamura, the University of Tokyo, for the recruitment of patients.

\section{References}

1 Mohler JL, Armstrong AJ, Bahnson RR, D’Amico AV, Davis BJ, Eastham JA, Enke CA, Farrington TA, Higano CS, Horwitz EM, Hurwitz M, Kane CJ, Kawachi MH, Kuettel M, Lee RJ, Meeks JJ, Penson DF, Plimack ER, Pow-Sang JM, Raben D, Richey S, Roach M, 3rd, Rosenfeld S, Schaeffer E, Skolarus TA, Small EJ, Sonpavde G, Srinivas S, Strope SA, Tward J, Shead DA and Freedman-Cass DA: Prostate cancer, version 1.2016. J Natl Compr Canc Netw 14(1): 19-30, 2016.

2 Mottet N, Bellmunt J, Bolla M, Briers E, Cumberbatch MG, De Santis M, Fossati N, Gross T, Henry AM, Joniau S, Lam TB, Mason MD, Matveev VB, Moldovan PC, van den Bergh RCN, Van den Broeck T, van der Poel HG, van der Kwast TH, Rouviere O, Schoots IG, Wiegel T and Cornford P: Eau-estro-siog guidelines on prostate cancer. Part 1: Screening, diagnosis, and local treatment with curative intent. Eur Urol 71(4): 618-629, 2017.

3 Na R, Zheng SL, Han M, Yu H, Jiang D, Shah S, Ewing CM, Zhang L, Novakovic K, Petkewicz J, Gulukota K, Helseth DL, Jr., Quinn M, Humphries E, Wiley KE, Isaacs SD, Wu Y, Liu X, Zhang N, Wang CH, Khandekar J, Hulick PJ, Shevrin DH, Cooney KA, Shen Z, Partin AW, Carter HB, Carducci MA, Eisenberger MA, Denmeade SR, McGuire M, Walsh PC, Helfand BT, Brendler CB, Ding Q, Xu J and Isaacs WB: Germline mutations in atm and brca $1 / 2$ distinguish risk for lethal and indolent prostate cancer and are associated with early age at death. Eur Urol 71(5): 740-747, 2017.

4 Rubicz R, Zhao S, Wright JL, Coleman I, Grasso C, Geybels MS, Leonardson A, Kolb S, April C, Bibikova M, Troyer D, Lance R, Lin DW, Ostrander EA, Nelson PS, Fan JB, Feng Z and Stanford JL: Gene expression panel predicts metastaticlethal prostate cancer outcomes in men diagnosed with clinically localized prostate cancer. Mol Oncol 11(2): 140-150, 2017.

5 Epstein JI, Feng Z, Trock BJ and Pierorazio PM: Upgrading and downgrading of prostate cancer from biopsy to radical prostatectomy: Incidence and predictive factors using the modified gleason grading system and factoring in tertiary grades. Eur Urol 61(5): 1019-1024, 2012.

6 Jackson W, Hamstra DA, Johnson S, Zhou J, Foster B, Foster C, Li D, Song Y, Palapattu GS, Kunju LP, Mehra R and Feng FY: Gleason pattern 5 is the strongest pathologic predictor of recurrence, metastasis, and prostate cancer-specific death in patients receiving salvage radiation therapy following radical prostatectomy. Cancer 119(18): 3287-3294, 2013.

7 Patel AA, Chen MH, Renshaw AA and D'Amico AV: Psa failure following definitive treatment of prostate cancer having biopsy gleason score 7 with tertiary grade 5. JAMA 298(13): 1533$1538,2007$.

8 Taguchi S, Shiraishi K, Fukuhara H, Nakagawa K, Morikawa T, Naito A, Kakutani S, Takeshima Y, Miyazaki H, Nakagawa T, Fujimura T, Kume $\mathrm{H}$ and Homma Y: Impact of gleason pattern 5 including tertiary pattern 5 on outcomes of salvage treatment for biochemical recurrence in $\mathrm{pt} 2-3 \mathrm{n} 0 \mathrm{~m} 0$ prostate cancer. Int $\mathrm{J}$ Clin Oncol 21(5): 975-980, 2016.

9 D'Amico AV, Whittington R, Malkowicz SB, Schultz D, Blank K, Broderick GA, Tomaszewski JE, Renshaw AA, Kaplan I, Beard CJ and Wein A: Biochemical outcome after radical prostatectomy, external beam radiation therapy, or interstitial radiation therapy for clinically localized prostate cancer. Jama 280(11): 969-974, 1998.

10 Fujimura T, Menon M, Fukuhara H, Kume H, Suzuki M, Yamada Y, Niimi A, Nakagawa T, Igawa Y and Homma Y: Validation of an educational program balancing surgeon training and surgical quality control during robot-assisted radical prostatectomy. Int J Urol 23(2): 160-166, 2016.

11 Naito S, Kuroiwa K, Kinukawa N, Goto K, Koga H, Ogawa O, Murai $M$ and Shiraishi $T$ : Validation of partin tables and development of a preoperative nomogram for japanese patients with clinically localized prostate cancer using 2005 international society of urological pathology consensus on gleason grading: Data from the clinicopathological research group for localized prostate cancer. J Urol 180(3): 904-909; discussion 909-910, 2008.

12 Fujimura T, Takahashi S, Urano T, Takayama K, Sugihara T, Obinata D, Yamada Y, Kumagai J, Kume H, Ouchi Y, Inoue S and Homma Y: Expression of androgen and estrogen signaling components and stem cell markers to predict cancer progression and cancer-specific survival in patients with metastatic prostate cancer. Clin Cancer Res 20(17): 4625-4635, 2014.

13 Borhan W and Epstein JI: Significance of gleason score 7 with tertiary pattern 5 at radical prostatectomy. Urology 100: 175179, 2017.

14 Jang WS, Yoon CY, Kim MS, Kang DH, Kang YJ, Jeong WS, Abalajon MJ, Ham WS and Choi YD: The prognostic role of tertiary gleason pattern 5 in a contemporary grading system for prostate cancer. Prostate Cancer Prostatic Dis 20(1): 93-98, 2017.

15 Abdollah F, Sood A, Sammon JD, Hsu L, Beyer B, Moschini M, Gandaglia G, Rogers CG, Haese A, Montorsi F, Graefen M, Briganti A and Menon M: Long-term cancer control outcomes in patients with clinically high-risk prostate cancer treated with robotassisted radical prostatectomy: Results from a multi-institutional study of 1100 patients. Eur Urol 68(3): 497-505, 2015.

16 Alberts AR, Bokhorst LP, Kweldam CF, Schoots IG, van der Kwast TH, van Leenders GJ and Roobol MJ: Biopsy undergrading in men with gleason score 6 and fatal prostate cancer in the european randomized study of screening for prostate cancer rotterdam. Int J Urol 24(4): 281-286, 2017.

17 Beauval JB, Ploussard G, Cabarrou B, Roumiguie M, Ouzzane A, Gas J, Goujon A, Marcq G, Mathieu R, Vincendeau S, Cathelineau X, Mongiat-Artus P, Salomon L, Soulie M, Mejean A, de La Taille A, Roupret M and Rozet F: Improved decision making in intermediate-risk prostate cancer: A multicenter study on pathologic and oncologic outcomes after radical prostatectomy. World J Urol 35(8): 1191-1197, 2017. 
18 Zhao SG, Chang SL, Spratt DE, Erho N, Yu M, Ashab HA, Alshalalfa M, Speers C, Tomlins SA, Davicioni E, Dicker AP, Carroll PR, Cooperberg MR, Freedland SJ, Karnes RJ, Ross AE, Schaeffer EM, Den RB, Nguyen PL and Feng FY: Development and validation of a 24-gene predictor of response to postoperative radiotherapy in prostate cancer: A matched, retrospective analysis. Lancet Oncol 17(11): 1612-1620, 2016.

19 Taguchi S, Fukuhara H, Shiraishi K, Nakagawa K, Morikawa T, Kakutani S, Takeshima Y, Miyazaki H, Fujimura T, Nakagawa $\mathrm{T}$, Kume $\mathrm{H}$ and Homma $\mathrm{Y}$ : Radical prostatectomy versus external beam radiotherapy for ct $1-4 \mathrm{n} 0 \mathrm{~m} 0$ prostate cancer: Comparison of patient outcomes including mortality. PLoS One 10(10): e0141123, 2015

20 Taguchi S, Shiraishi K, Fukuhara H, Nakagawa K, Morikawa T, Naito A, Kakutani S, Takeshima Y, Miyazaki H, Nakagawa T, Fujimura T, Kume H and Homma Y: Optimal timing of salvage radiotherapy for biochemical recurrence after radical prostatectomy: Is ultra-early salvage radiotherapy beneficial? Radiat Oncol 11: 102, 2016.

21 Taguchi S, Fukuhara H, Azuma T, Suzuki M, Fujimura T, Nakagawa T, Ishikawa A, Kume H, Igawa Y and Homma Y: Ultra-early versus early salvage androgen deprivation therapy for post-prostatectomy biochemical recurrence in pt $2-4 \mathrm{n} 0 \mathrm{~m} 0$ prostate cancer. BMC Urol 14: 81, 2014.
22 Fossati N, Karnes RJ, Cozzarini C, Fiorino C, Gandaglia G, Joniau S, Boorjian SA, Goldner G, Hinkelbein W, Haustermans K, Tombal B, Shariat S, Karakiewicz PI, Montorsi F, Van Poppel H, Wiegel T and Briganti A: Assessing the optimal timing for early salvage radiation therapy in patients with prostate-specific antigen rise after radical prostatectomy. Eur Urol 69(4): 728-733, 2016.

23 Lane JA, Donovan JL, Davis M, Walsh E, Dedman D, Down L, Turner EL, Mason MD, Metcalfe C, Peters TJ, Martin RM, Neal DE and Hamdy FC: Active monitoring, radical prostatectomy, or radiotherapy for localised prostate cancer: Study design and diagnostic and baseline results of the protect randomised phase 3 trial. Lancet Oncol 15(10): 1109-1118, 2014.

Received September 29, 2018

Revised October 17, 2018

Accepted October 18, 2018 